\title{
Consciously cutting to the bone of SA's surgical/anaesthetic delivery
}

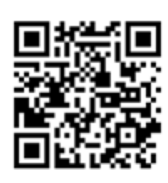

A critical mass of key surgeons and anaesthetists met at the University of the Witwatersrand in December last year to start gauging the country's paucity of access to safe, affordable surgical and anaesthetic care, guided by recently crafted global improvement templates.

With South Africa (SA) at less than half of the Lancet Commission on Global Surgery's recommended 'norm' for a national surgical workforce $(20 / 100000$ population) and no change in the local ratio likely any time soon, upskilling of non-specialists and task sharing emerged as urgent priorities. A searching consensus was reached on the need to support, upskill and recognise the pivotal

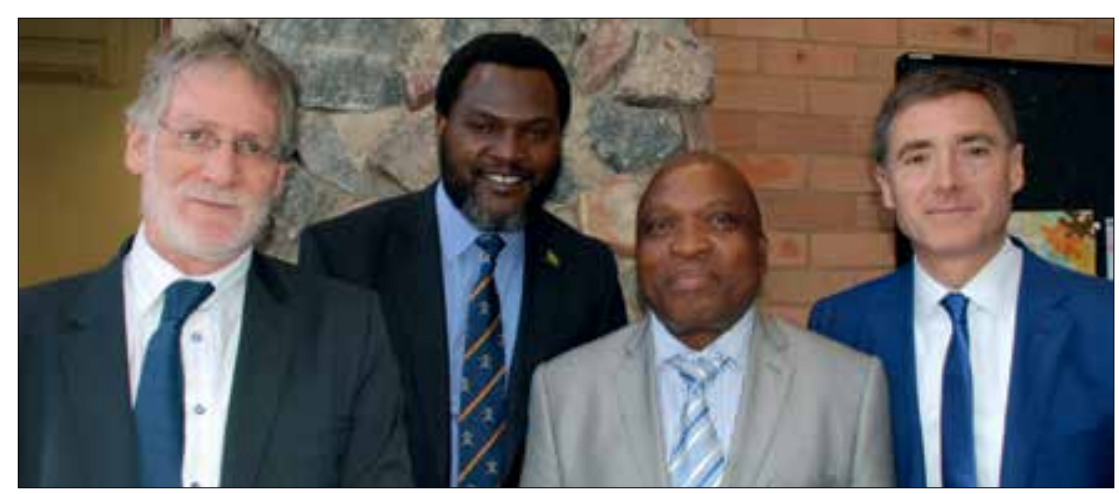

From left to right: Prof. Martin Smith, Dr Emmanuel Makasa, Deputy Minister of Health Dr Joe Phaahla and Prof. John Meara.

role played by medical officers (MOs), whose retention in the district hospital system was

'vital' to delivering surgery and anaesthesia. Key delegates, including Dr Terence Carter, 


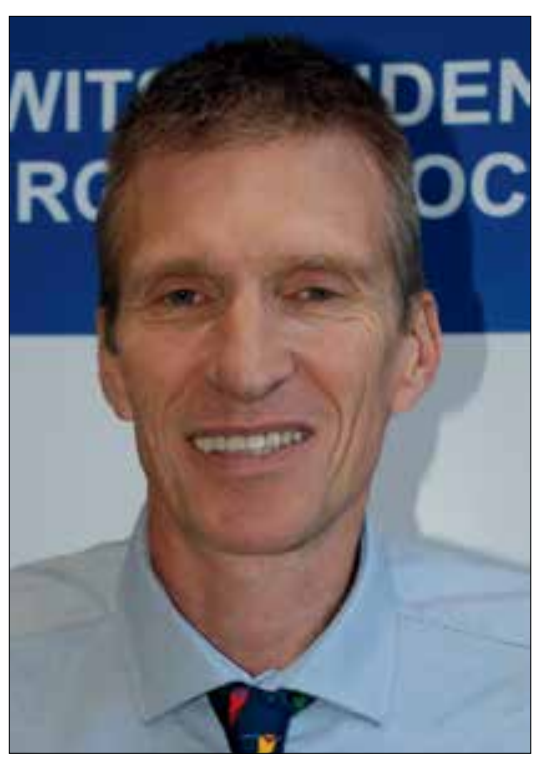

Prof. Eckhart Buchmann.

Deputy Director-General: Hospitals Tertiary Service and Workforce Management, Prof. Mac Lukhele, Head of the School of Clinical Medicine at the University of the Witwatersrand (Wits), seminar convenor Prof. Martin Smith, Academic Head of Surgery at Wits, and Dr Richard Cooke, Acting Director of the Wits Centre for Rural Health, plus Dr Carol Marshal, recently resigned chief of the Office for Healthcare Standards Compliance (OHSC) and now heading the district specialist-led outreach teams, contributed unique perspectives on how this could be done.

Delivering the keynote speech, national Deputy Minister of Health Dr Joe Paahla said that with surgical conditions accounting for $30 \%$ of the global burden of disease, increasing the pool of surgical and anaesthetic skills in SA would 'save a lot of lives'. A veteran of deep rural hospital service, Paahla said that skills in trauma, fractures, obstetrics and gynaecology were among the basics required to handle events such as vehicle accidents, ectopic pregnancies or a ruptured appendix. In acute urinary retention, extreme pain could be relieved just by knowing how to insert a catheter: 'If nobody knows how to do that, it can be very frustrating.' He said it was 'critical' to put together a package of basic surgical skills that could be used in district and regional hospitals, and his department was committed to partner with the local and international bodies whose landmark work and pragmatic targets had sparked the local seminar. With SA's 'mega-challenge' of low economic growth, creativity and innovation would be essential in prioritising use of available resources. Protection against catastrophic out-of-pocket payments for patients was a major challenge, and Paahla appealed to delegates to pay attention to the social determinants of health that increase surgical and anaesthetic risk. He suggested encouraging specialists to leave their tertiary environments to do 6 - 12-month stints in outlying hospitals, thus 'reversing the flow' of district incumbents to them, while maintaining rural healthcare delivery. He said the National Health Insurance White Paper recognised the need for 'this kind of specialist support' (via the district clinical specialist outreach teams), 'so this conference comes at just the right time'.

Carter said universities were failing to aim specialist training at generalists, spending too much time on training subspecialists, 'something we'll be pushing them to change'. The package of care at district hospitals needed revision to upgrade the availability of surgical care, followed by 'a look at the skill sets we need. He noted that while improving access to safe surgery was vital, there was a more critical shortage of anaesthetic skills.

Lukhele said the dismally low ratio of healthcare workers to population demanded a 'complete paradigm shift' where interprofessional healthcare education, along with upgraded skillsets, were prioritised. He said that increasing numbers of generalists while also harnessing clinical associates to do caesarean sections or circumcisions (under initial supervision) would increase patient access to care.

Cooke said the widespread phenomenon of community service officers wanting to 'escape' into specialisation when their obligatory stint was over was driven by the lack of support they received from senior staff and the system itself during their tenure. 'For me it's not about the absolute numbers of MOs or comserves, it's about attrition and vulnerability - you just haemorrhage staff very quickly. He suggested offering a postgraduate diploma in primary healthcare as a 'stepping stone.'

Forum delegates heard from Prof. John G Meara, Kletjian Professor of Global Health and Social Medicine in the field of Global Surgery at Harvard Medical School, that $15 \%$ of all deaths globally are due to surgically preventable conditions, with a third of the world's population receiving just $6.3 \%$ of all surgical procedures. World Bank President Jim Kim had said that $28-32 \%$ of the global burden of disease was from surgical conditions, concluding that investing in surgery was hugely cost-effective, saved lives and promoted economic growth. The Wits national forum was fortuitously held a week before the release of the White Paper on National Health Insurance.

\section{SA surgical forum} 'catching the global wave'

Smith said the seminal event was the outflow of a confluence of the Lancet Commission's global surgery findings in April last year, a resolution on essential surgery by the World Health Assembly a month later, and the World Bank's unprecedented focus on surgery in its 3rd version of Disease Control Priorities. He said the role of surgery in achieving universal access to healthcare, with vital devolution down to primary healthcare and district hospital levels, was crucial to overall integration. Meara said the Lancet Commission had 'come up with five deceptively simple' indicators. These were what percentage of the population lived within 2 hours of accessing essential surgery, surgical volumes (procedures done in an operating room per 100000 population), protection against impoverishing expenditure, the surgical, anaesthetist and obstetrician (SAO) density per 100000 population, and the postoperative mortality rate. It was estimated that globally five billion people could not access safe surgery when they needed it. 'We need timely access, capacity, proper skills and affordability - far too many countries cannot jump through these hoops', he added. Several surgeons at regional and district SA hospitals said that while a process of auditing district hospital staffing levels had already begun, it was aimed at coming up with norms when a minimum staffing level was urgently required. Marshal, who resigned as founding CEO of the OHSC in June last year, only to take up leadership of the pivotal National Health Insurance's district specialist-led outreach program in December, said that many facilities could not provide safe medical care because of staff shortages, while others were overstaffed according to workload. Prof. Ian Couper, Director of the Wits Centre

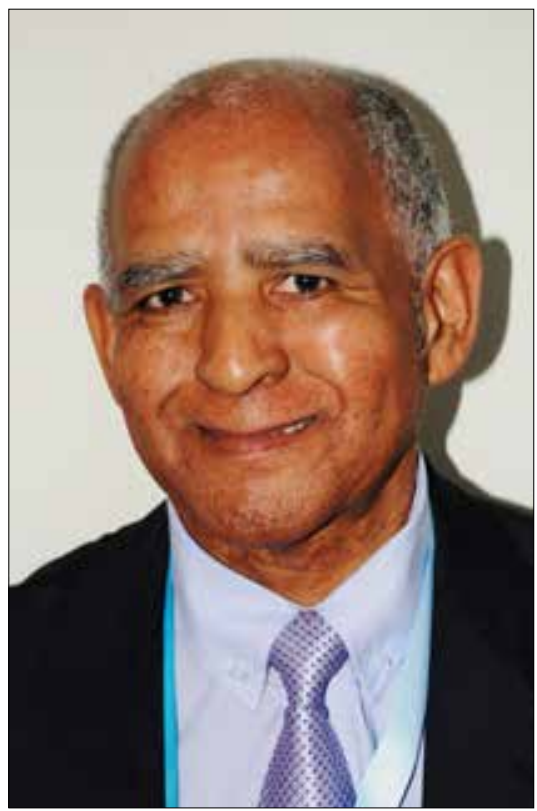

Dr Terence Carter, Deputy Director-General: Hospitals Tertiary Service and Workforce Management. 
for Rural Health, added that even overstaffed district hospitals were failing to provide the clinics they served with standard once-a-week visits.

\section{No basic skills? Close the hospital down - former Bara obstetrics chief}

Echoing Smith's appeal to influence government policy with hard data, Prof. Eckart Buchmann, a former senior obstetrician at Chris Hani Baragwanath Academic Hospital and now in private medicolegal practice, said that every single district hospital in the country had to be measured on its ability to perform basic caesarean sections and laparotomies: 'If it can't, it must be closed. That's crucial in getting to where we want to.' Dr Mark Blecher, Health Chief at National Treasury, urged delegates to come up with a basic surgery costing plan in order to make an unprecedented case for the discipline to his department. 'Calling it the neglected stepchild is quite a strange term in a way; intriguing when one argues that the costing of basic surgery packages is not factored in very strongly? $\mathrm{He}$

\section{Limpopo's tragic tale of C-section deaths}

An alarming example of maternal deaths due to dismal staffing, low skills levels and a total absence of supervisory support is Limpopo Province, where the National Committee for Confidential Enquiry into Maternal Deaths found that $10 \%$ of all caesarean section patients died due to anaesthesia in 2014. That's over four times higher than the national public sector C-section (preventable) death rate from anaesthesia (2.4\%). Mostly unsupervised community service doctors with no anaesthetic training were performing on average between two and three C-sections per week in the province's 70 mainly rural district hospitals, conducting spinal blocks with no airway skills, no intubation equipment and insufficient drugs. Limpopo has a $70 \%$ vacancy rate for both general practitioners and specialists, with just four anaesthetists: one a district specialist (mainly administration), two at the local university (one about to retire) and one in a regional hospital. A 2014 audit revealed SA to have 1300 anaesthetists, two-thirds of them in private practice with 360 in training. Nonspecialists in the discipline are estimated at 1200 , with varying degrees of commitment.

Prof. Christina Lundgren, Clinical Head of Anaesthesia at Chris Hani Baragwanath Academic Hospital, and Natalie Zimmelman, CEO of the South African Society of Anaesthesiologists (SASA), told Izindaba that emphasised that SA had (financial) health packages 'for everything, from maternal and child health, to HIV, tuberculosis and malaria we have budgets drawn up annually by people who specialise in HIV economics. He said that trauma surgery having recently been declared a specialty by the Colleges of Medicine had had a very positive impact on financing. 'Surgeons seem to hate admin', he joked, adding that there had been a 'great distance historically' between surgeons and public health - something he commended the forum on trying to correct. Blecher revealed that there were no qualified surgeons in the national health department administration, adding that it would be helpful if somebody was appointed 'who understood something about this and brought the necessary skills into financing and planning?

\section{Treasury health chief: appoint a surgical services co-ordinator}

Blecher and his Treasury colleagues believed that there was a role for a surgical service co-ordinator. 'I mean, do we know how many trauma centres are needed? It's difficult to answer how much money is needed for surgical services. Money seems to follow a well-costed plan - a national surgical plan would be a good idea.' He added that the Lancet Commission report gave clear guidelines that needed tailoring to SA needs. 'We have to ask why we are not costing surgery fully in all these basic health packages - it's certainly cost-effective,' he added. Marshal made the point that if we miss this boat, we'll regret it. Surgery has to be an integral part of what everybody already does.' She said the opening of the Wits forum by the Deputy Minister of Health could be leveraged in getting government on board. Smith said a task team would be set up to work on priorities that emerged from the forum's various workshops, incorporating all key stakeholders to help integrate surgery into the national primary healthcare model.

\section{Chris Bateman \\ chrisb@hmpg.co.za}

S Afr Med J 2016;106(2):132-134. DOI:10.7196/SAMJ.2016.v106i2.10526

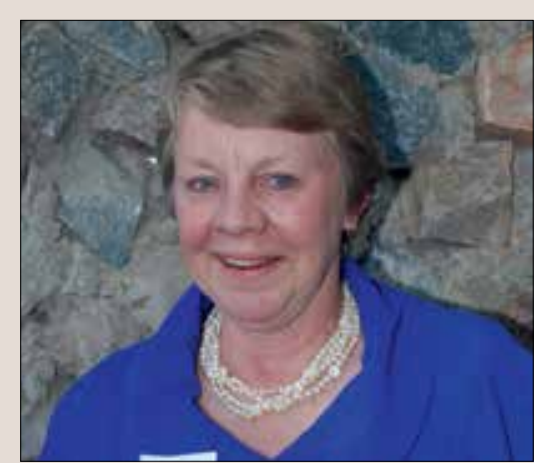

Prof. Christina Lundgren.

a multistakeholder task team was immediately formed, drawing up a plan for university-led support and reaching a 'memo of understanding' with Limpopo. 'I feel desperately sorry for the comserves. When we said to Province, can't they please get 2 months of training in the tertiary hospitals, they said it was against policy - so they all had to go to district hospitals without training. The upshot was that nobody took responsibility for anaesthesia, with a survey among comserves and MOs revealing that even if they were doing a spinal block, they were unable to convert to a general anaesthetic or resuscitate. Low C-section volumes contributed to the overall lack of skills. 'It was whoever's there on the day - nobody was owning it,' Lundgren added. At one stage, the expert duo told Izindaba, the province had even considered using dentists on overtime to provide anaesthesia - but they recognised very quickly that was not a solution. It's probably cheaper and quicker to train existing MOs and even comserves in an anaesthesia diploma than it would be train nurse-anaesthesiologists', observed Lundgren. The universities of the Witwatersrand and Pretoria had since agreed to work with the province to help train and mentor comserves and MOs, and provide equipment, workshops, guidelines and short courses. Added Lundgren: 'There are not enough anaesthesiologists to go out and train, so they have to come to Bara - the province's biggest worry is service delivery while we train. Zimmelman said what she found 'most interesting' was that it was actually possible to give a GP (or MO) sufficient experience and skill via an intensive and continuous 6-month diploma.

Lundgren said Limpopo's tragic story of avoidable deaths was an extreme example of the estimate that one-third of the world's rural populations had no access to essential surgery, with more than a third having no access to anaesthesia. 'We are the neglected stepchild, with governments reluctant to invest in anaesthesia (and surgery) - this and the lack of accessibility to theatres is a very sad reflection. She said that worldwide, the anaesthetic mortality rate was $1 \%$. The ratio for anaesthesiology specialists to population in SA stood at 2:100 000, increasing to 3.5 for specialists and GPs (v. 10:100 000 in the UK, Europe and Australia, less than 0.05 in Zambia, and 0.35 for all anaesthesia providers in Zimbabwe). 